\title{
DOR E DESEJO NA TEORIA FREUDIANA DO APARELHO PSÍQUICO E DAS NEUROSES
}

\author{
Pain and wish in the freudian theory of the \\ psychic apparatus and of neuroses
}

\section{Fátima Caropreso}

Professora adjunta da Faculdade de Ciências Humanas (FCH) da Universidade Federal da Grande Dourados (UFGD), Dourados, MS - Brasil, e-mail: fatimacaropreso@uol.com.br

Ao Professor Luiz Roberto Monzani, cujo trabalho inspirou esse artigo.

\section{Resumo}

Este artigo tem como objetivo analisar o papel concedido por Freud à vivência de satisfação e à vivência de dor no desenvolvimento dos processos psíquicos normais e patológicos em diferentes momentos de sua obra. Pretendemos argumentar que, na etapa final de sua teoria, mais especificamente no texto Inibição, Sintoma e Angústia, de 1926, Freud passa a situar experiências traumáticas reais na origem do psiquismo e das neuroses, o que representa, de certa forma, uma retomada e colocação em primeiro plano da hipótese da "vivência de dor", formulada no Projeto de 
uma psicologia (1895/1950). Com essa retomada da hipótese da vivência de dor, Freud enfatiza o papel de um fator biológico inevitável - o desamparo e prematuração do ser humano ao nascer - na predisposição à neurose, o que representa uma modificação significativa da teoria sustentada, ao longo da maior parte de sua obra, segundo a qual o desejo e a oposição que as exigências da cultura impõem a esse seriam os principais fatores determinantes das neuroses.

Palavras-chave: Psicanálise freudiana. Vivência de satisfação. Vivência de dor. Aparelho psíquico. Neuroses.

\begin{abstract}
The objective of this paper is to discuss the role played by the experience of satisfaction and by the experience of pain in the development of both normal and pathological psychic processes in different moments of Freud's work. I argue that, in the final stage of Freud's workmore specifically, from Inhibitions, Symptoms, and Anxiety (1926) onwards -, real traumatic experiences were supposed lie at the heart of neuroses and of the psyche itself. In a certain way, this returned to the foreground the "experience of pain" hypothesis, earlier formulated in the Project for a Scientific Psychology (1895). Here Freud stresses the role played by an unavoidable biological factor - the helplessness and the prematurity of the human being at birth - in the predisposition to neurosis. This emphasis meant a significant change in the theory he had upheld for the greater part of his career, according to which desires and the constraints imposed on them by cultural demands were the main determinants of neuroses.
\end{abstract}

Keywords: Freudian psychoanalysis. Experience of satisfaction. Experience of pain. Psychic apparatus. Neuroses.

A hipótese de que haveria uma "vivência de dor", que seria estruturante do psiquismo e que estaria na base das neuroses, está presente nas primeiras especulações de Freud - mais especificamente no Projeto de uma psicologia (1895/1950) - mas é deixada de lado durante grande parte de sua obra. Já em A interpretação dos sonhos (1900), apenas o papel da vivência 
de satisfação - e, portanto, apenas o papel do desejo - é levado em conta nas hipóteses ali apresentadas sobre o desenvolvimento e o funcionamento do psiquismo. Sabemos que essa modificação na teoria decorreu, em parte, do abandono da teoria da sedução e do reconhecimento do papel que a fantasia desempenha na gênese das neuroses. No entanto, a partir de Além do princípio do prazer (1920), Freud volta a refletir sobre o papel que a vivência de dor então chamada de "trauma" - exerceria no psiquismo e, em Inibição, Sintoma e Angústia (1926), ele volta a colocar experiências traumáticas reais na base do funcionamento psíquico normal e patológico. Com isso, Freud enfatiza o papel de um fator biológico inevitável - o desamparo e prematuração do ser humano ao nascer - na predisposição à neurose, o que representa uma modificação significativa da teoria sustentada ao longo da maior parte de sua obra, segundo a qual o desejo e a oposição que as exigências da cultura impõem a esse seriam os principais fatores determinantes das neuroses. Nesse artigo, pretendemos analisar o papel concedido por Freud à vivência e satisfação e à vivência de dor no desenvolvimento dos processos psíquicos normais e patológicos em diferentes momentos de sua obra e discutir as implicações das modificações introduzidas em Inibição, Sintoma e Angústia para a concepção freudiana acerca da estruturação do psiquismo e da etiologia das neuroses.

\section{Dor e desejo estão na origem dos processos psíquicos}

No Projeto de uma psicologia (1895/1950), como se sabe, Freud formula a hipótese de uma "vivência de satisfação", que seria estruturante do funcionamento psíquico normal, e de uma "vivência de dor", que seria estruturante do funcionamento psíquico patológico. ${ }^{1}$ A vivência de satisfação consistiria na satisfação de uma necessidade, como a obtenção de alimento, no caso da fome. Tal vivência teria como consequência, em primeiro lugar, o término do desprazer decorrente da ocupação, por estímulos endógenos, da parte do sistema de memória diretamente ligada ao somático (sistema psi do núcleo); em segundo lugar, a constituição - na parte do sistema de memória que estaria em ligação com o sistema de percepção phi e que receberia estímulos exógenos (psi do manto) - de uma representação do objeto externo, cuja percepção fora simultânea à experiência de satisfação; e, em terceiro, a formação de uma representação do movimento reflexo executado. Entre essas

Para um esclarecimento detalhado das hipóteses do "Projeto...", ver SIMANKE, 2007. 
duas representações de psi do manto e os neurônios nucleares ficaria estabelecida uma facilitação, pelo fato de que as primeiras se teriam constituído simultaneamente à ocupação de psi do núcleo. Uma vez estabelecidas tais facilitações, quando o estado de excitação no núcleo reaparecesse, o processo excitatório seguiria o caminho por elas definido e ocuparia as representações em psi do manto. Esta tendência para investir as representações de objeto é o que Freud chama de "desejo". Nesse caso, não havendo nenhuma inibição, a ocupação da representação de objeto por causa da animação de desejo seria muito intensa, de modo que o sistema responsável pela produção de qualidades sensoriais (sistema ômega) forneceria signos de qualidade, produzindo, assim, uma alucinação. Em consequência dessa alucinação, a ação reflexa - no caso, a sucção - seria executada e, nessas condições, provocaria uma frustração, uma vez que o desprazer decorrente da estimulação em psi do núcleo não cessaria. O bebê ficaria, então, num estado de "desamparo". Esse modo de funcionamento desadaptativo, que conduz à alucinação e à vã descarga motora, é chamado por Freud de "processo primário". Para a sobrevivência do indivíduo, seria necessário haver uma alteração nessa tendência primária do processo associativo, de modo que a representação de desejo não fosse mais tão intensamente ocupada, tornando possível ao eu diferenciar entre uma rememoração e uma percepção e evitando, assim, o investimento das representações de movimento na ausência do objeto desejado na realidade. Ou seja, a sobrevivência exigiria a substituição do processo primário pelo secundário.

A dor consistiria na irrupção de grandes quantidades na direção do sistema de memória $p s i$, como consequência da falha dos dispositivos de proteção do aparelho contra quantidades exógenas - as próprias terminações sensoriais nervosas, segundo Freud. Esse processo produziria, em primeiro lugar, um grande aumento no nível da excitação no sistema de memória, sentido como desprazer; em segundo, uma inclinação para a eliminação da excitação pela via reflexa e, em terceiro, uma facilitação entre esses caminhos de eliminação e a representação do objeto que provocou a dor (objeto hostil). Uma vez ocorrida essa vivência de dor, quando a representação do objeto hostil fosse ocupada novamente a partir de uma percepção ou por associação com outras representações, ocorreria uma liberação de quantidade no aparelho que geraria desprazer - processo esse chamado de "afeto" - e uma inclinação para a desocupação da representação do objeto hostil pela via reflexa, que é chamada de "defesa primária". Então, assim como a vivência de satisfação teria como 
consequência o surgimento do "estado de desejo", o qual inicialmente conduziria à alucinação e à vã descarga motora, a vivência de dor teria como consequência o surgimento do "afeto" e a defesa primária excessiva. A produção do afeto pela ocupação do objeto hostil seria prejudicial nos casos em que tal ocupação não fosse estimulada a partir do mundo externo, mas apenas a partir do interior o aparelho, ou seja, quando se tratasse de uma mera recordação. Portanto, esse modo primário de funcionamento também seria inibido com o estabelecimento do processo secundário.

O processo secundário surgiria a partir da inibição e do redirecionamento do processo primário. Com as repetições da vivência de satisfação e o consequente desamparo, o eu aprenderia a não ocupar tão intensamente a representação de desejo e as representações de movimento a ela associadas. Como consequência, certo nível de quantidade seria retido no núcleo de y, isto é, parte da excitação passaria a permanecer em "estado ligado". Com esse armazenamento de quantidade, o curso associativo passaria a ser direcionado pelo eu e não mais seguiria unicamente pelas vias mais bem facilitadas. A partir de então, a ocupação da representação hostil e a defesa primária excessiva passariam a ser inibidas. A inibição da alucinação e da descarga motora seriam condicionadas biologicamente pelo desprazer. Já a inibição da ocupação intensa da representação do objeto hostil e da produção de afeto dela decorrente seria um processo gradual, que pressuporia o estabelecimento da excitação em estado ligado (CAROPRESO; SIMANKE, 2006). Após o domínio do eu sobre as representações relacionadas à vivência de dor estar consolidado, a liberação de desprazer, diante da reocupação do objeto hostil, seria limitada a um mínimo que permitisse apenas sinalizar ao curso associativo que aquele caminho conduz ao desprazer e deve ser evitado. Assim, uma "defesa normal" substituiria, no processo secundário, a defesa primária que teria lugar no processo primário.

Na segunda parte do Projeto..., Freud explica a produção dos sintomas da histeria a partir da falha do mecanismo de defesa do eu. No caso da defesa normal, uma representação associada a uma vivência de dor seria em geral evitada no curso do processo do pensar, embora ela pudesse voltar a se tornar consciente se evocada por estímulos externos. $\mathrm{Na}$ repressão que está na origem da histeria, diferentemente, a recordação patógena estaria totalmente excluída da consciência. No seu lugar, apareceria uma outra representação a ela associada, a qual seria acompanhada pela produção de afeto. Nesse caso, a liberação de afeto seria incitada por uma representação substitutiva que seria um símbolo de 
outra que se encontraria reprimida e, por isso, a sua inibição não seria possível. Tratar-se-ia de um "processo primário póstumo".

Freud argumenta que esse processo resultaria de uma falha do mecanismo normal de defesa, a qual se deveria ao fato de que as representações patógenas inconscientes não teriam sido traumáticas, em sua origem, ou seja, não teriam originariamente feito parte de uma vivência de dor, mas teriam adquirido o caráter traumático apenas posteriormente após a emergência da sexualidade. Como se sabe, no momento da redação do Projeto..., Freud trabalhava com a hipótese de que haveria experiências de abuso sexual efetivamente ocorridas na gênese da histeria e trabalhava também com a hipótese de que a sexualidade só surge na puberdade. Assim, apenas com a emergência da sexualidade na puberdade, as experiências sexuais infantis poderiam ser compreendidas enquanto tais e, só então, adquiririam o caráter de um trauma. Quando a recordação da experiência de sedução fosse incitada, ela produziria uma excitação sexual que seria convertida em angústia. $\mathrm{O}$ mecanismo de defesa entraria em ação para defender o aparelho desse surgimento de angústia; no entanto, seu êxito seria apenas parcial, uma vez que, embora a recordação efetivamente traumática fosse reprimida, permanecendo inconsciente, o afeto continuaria sendo evocado em associação com uma outra representação, aparentemente inócua, que estaria associada à primeira. Portanto, essa defesa imperfeita levaria à produção do sintoma.

Então, nesse momento da teoria freudiana, a histeria é explicada como efeito de um trauma, a partir do modelo da vivência de dor. Experiências traumáticas reais relacionadas à sexualidade estariam na origem da repressão e da neurose, embora o caráter traumático só viesse a se acrescentar a tais experiências posteriormente. Quando Freud conclui que as representações reprimidas não são produtos de experiências reais, mas sim de fantasias sexuais infantis, e que, portanto, é necessário admitir que a sexualidade já se manifesta na infância e que a repressão atua sobre desejos, e não sobre experiências traumáticas realmente vivenciadas, o modelo da vivência de dor parece tornarse inadequado para explicar a neurose. Durante um longo período de sua obra, a reação do aparelho psíquico a experiências dolorosas reais não será tematizada e o papel da vivência de satisfação, no desenvolvimento dos processos psíquicos, permanecerá em primeiro plano na teoria. Contudo, a partir de 1920, Freud retoma a questão do efeito do trauma na constituição dos processos psíquicos e, como procuraremos argumentar, em Inibição, Sintoma e Angústia (1926), a vivência de dor, de certa forma, volta a ser pensada como estando na origem do psiquismo e da neurose. 


\section{Apenas o desejo está na origem do aparelho psíquico}

Na carta a Fliess, de 6 de dezembro de 1896 (Carta 52), Freud formula a hipótese de que o mecanismo psíquico se formaria a partir de um processo de estratificação sucessiva, isto é, de que os traços mnêmicos seriam sujeitos a reordenações, de acordo com novos nexos, de tempos em tempos. Essas "retranscrições" dariam origem a diferenciações no sistema de memória, as quais representariam a operação psíquica de épocas sucessivas da vida. Freud argumenta que haveria no mínimo três tipos de transcrições, as quais são representadas no esquema apresentado no texto como "Ps" (signos de percepção), "Ics" (inconsciência) e "Pcs" (préconsciência). Esses sistemas estariam situados entre o órgão responsável pela percepção $(\mathrm{P})$ e a via motora $(\mathrm{M})$. Em cada um deles, as representações estariam ordenadas de acordo com princípios associativos diferentes.

No sistema de memória do Projeto..., toda facilitação seria determinada pela simultaneidade da incidência da quantidade nos neurônios e, portanto, a constituição das representações, assim como a associação entre representações se daria de acordo com relações de simultaneidade. $\mathrm{Na}$ carta 52, Freud sustenta que há associações que ocorrem de acordo com outros tipos de relações - como a causalidade, que seria o princípio associativo presente no sistema inconsciente -, e que a simultaneidade seria o princípio ativo apenas no primeiro sistema de memória. O nível mais elevado de organização das representações - o pré-consciente - seria aquele em que as associações linguísticas estariam presentes. Nesse nível, o pensamento poderia se tornar consciente, a partir da "ativação alucinatória" das associações linguísticas.

Esse processo de retranscrição ou de tradução dos traços mnêmicos poderia não ocorrer em relação a uma parte do material representacional, com a finalidade de evitar o desprazer que seria gerado por tal tradução. Isso é o que Freud chama de "repressão". As representações reprimidas seriam aquelas que não foram traduzidas - e, portanto, ficaram de fora das transcrições posteriores, ou seja, ficaram excluídas dos processos associativos dominantes - devido ao desprazer que seria produzido. ${ }^{2}$ Como consequência dessa falta de tradução, as

\footnotetext{
A ideia, apresentada no "Projeto de uma psicologia", de que o funcionamento psíquico é governado pela tendência a evitar o aumento do nível de excitação no aparelho, ou a evitar o desprazer, é retomada na carta 52.
} 
representações não chegariam a ter acesso às representações-palavra, permanecendo insuscetíveis de se tornarem conscientes pela via normal do pensamento. A repressão, segundo Freud, seria uma "defesa patológica" e a "defesa normal" seria aquela que ocorreria dentro de um mesmo sistema de transcrições, a partir da inibição do desprazer gerado pela representação.

Essa hipótese elaborada por Freud de que as representações seriam reorganizadas de tempos em tempos e de que essa reorganização poderia produzir uma mudança na qualidade de certos traços de memória, torna possível explicar a mudança qualitativa de uma recordação (de prazerosa em desprazerosa) sem que seja necessário relacioná-la ao despertar da sexualidade. Não é mais necessário supor que a emergência da sexualidade confere um caráter traumático a uma vivência, em sua origem, inócua. Nem é necessário vincular a repressão a experiências efetivamente vivenciadas. As hipóteses da carta 52 abrem a possibilidade de se pensar que a repressão atua sobre desejos (e não sobre experiências reais) que passaram a evocar desprazer por causa de novas aquisições psíquicas, de novas associações que se estabeleceram, sob a influência da educação, da aquisição dos valores morais. Enfim, não há mais a necessidade de se recorrer ao modelo da vivência de dor para pensar a repressão e o surgimento da neurose. De fato, em a A interpretação dos sonhos (1900), assim como nos Artigos metapsicológicos (1915-1917), o desenvolvimento dos processos psíquicos normais e patológicos será pensado como sendo estruturado exclusivamente a partir do modelo da vivência de satisfação e do desejo que dela deriva. A vivência de dor é deixada de lado nessa fase da teoria.

Na seção B do capítulo 7 de A interpretação dos sonhos, Freud retoma a ideia da existência de vários sistemas de memória. Na carta 52, ele dissera que haveria no mínimo três sistemas. No esquema do capítulo 7, outros sistemas de memória são incluídos entre o sistema de percepção e o do inconsciente. Freud esclarece, nesse texto, que a representação tópica dos sistemas - isto é, a representação destes como lugares diferentes no aparelho - é uma representação auxiliar utilizada com fins didáticos e que, na verdade, os sistemas correspondem a processos diferentes. No início da seção F, ele afirma:

Se as consideramos com maior atenção, as elucidações psicológicas da seção anterior não nos sugerem a suposição da existência de dois sistemas perto do extremo motor do aparelho, mas sim de dois processos ou de dois modos no decurso da excitação. Para nós dá na mesma; sempre devemos estar dispostos a abandonar nossas representações auxiliares quando nos acreditamos em condições de substituí-las por alguma outra coisa que se aproxime mais da realidade desconhecida (FREUD, 1900, p. 610). 
Os dois últimos sistemas mnêmicos - entre os quais se situaria uma "censura" - seriam o Inconsciente (Ics) e o Pré-consciente (Pcs). Este último estaria ligado à consciência e governaria o acesso à motilidade voluntária. Como Freud afirma na passagem acima, esses sistemas corresponderiam a dois tipos de processos: o inconsciente corresponderia ao processo primário, que se caracterizaria pelo livre fluxo de quantidade, e o pré-consciente corresponderia ao processo secundário, que se caracterizaria pela retenção de uma parte da excitação nas representações. Portanto, a diferenciação entre dois "modos no decurso da excitação", mencionada na passagem anterior, seria aquela entre o estado "livre" e o estado "ligado" ou "quiescente" da quantidade. Apesar de ser uma representação menos rigorosa, a representação tópica deveria continuar sendo utilizada, argumenta Freud, uma vez que ela figura de maneira mais simples a diferenciação em questão.

O processo primário estaria presente no aparelho desde sua origem - ele representaria a tendência primordial a descarregar toda a excitação que o alcançasse - e o processo secundário se estabeleceria pouco a pouco a partir da inibição do primário. Essa inibição, no entanto, não seria total, pois, devido ao estabelecimento tardio do processo secundário, um grande segmento do material mnêmico permaneceria inacessível a esse último processo, argumenta Freud. Essas representações continuariam sendo alvo do processo primário e permaneceriam insuscetíveis de se tornarem conscientes pela via normal do pensamento, isto é, a partir da intermediação do pré-consciente. Outras representações se encontrariam nesse mesmo estado: aquelas que foram reprimidas. Mas estas teriam sido um dia pré-conscientes; no entanto, por se tornarem substitutas de representações inaceitáveis para o processo secundário, teriam sido excluídas desse último tipo de processo, voltando a ser governadas pelo processo primário. As representações do primeiro tipo seriam pré-condição para a existência dessas últimas.

Freud levanta a hipótese de que haveria um conjunto de

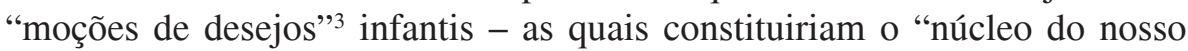
ser" - que permaneceriam inapreensíveis e não inibíveis pelo processo

3 No capítulo7, assim como no Projeto..., o desejo é pensado como consistindo na tendência de uma excitação para ocupar uma determinada representação-objeto. A ocupação desta representação consistiria em uma "realização de desejo". Segundo Laplanche (1982), uma "moção" seria uma excitação fixada em uma representação específica. 
secundário, por causa do estabelecimento tardio deste processo. Essas moções de desejo excluídas do processo secundário se dividiriam em dois grupos: aquelas cuja realização não seria desprazerosa para o pré-consciente e aquelas cuja realização produziria um desprazer, que o pré-consciente seria incapaz de evitar. As primeiras, embora não inibíveis e inapreensíveis ao processo secundário, seriam direcionadas por estes pelo caminho mais adequado. Já aquelas moções de desejo cuja realização tornara-se desprazerosa para o pré-consciente permaneceriam totalmente fora da influência desse sistema:

[...] entre estas moções de desejo indestrutíveis e não inibíveis que provêm do infantil se encontram também aquelas cujo cumprimento entrou em relação de contradição com as representações-meta do processo secundário. O cumprimento de tais desejos já não provocaria um afeto prazeroso, e sim um de desprazer e justamente esta mudança do afeto constitui a essência do que designamos "repressão (FREUD, 1900, p. 604).

Essas moções de desejo excluídas do Pcs manteriam sempre a aspiração de alcançar a consciência e a motilidade, isto é, de atingir a satisfação. Embora as representações originariamente associadas ao desejo inconsciente nunca chegassem a ser incorporadas ao processo secundário, a excitação a elas associada tentaria continuamente ingressar no Pcs. Por esse motivo, este sistema teria que manter uma pressão contínua no sentido oposto - o que mais tarde, nos Artigos metapsicológicos (1915), seria chamado de "contra-ocupação" - para se proteger contra o avanço da excitação inconsciente. Em alguns casos, no entanto, esse mecanismo de proteção falharia e a excitação de desejo conseguiria ingressar no processo secundário - isto é, ela conseguiria ocupar uma representação pré-consciente -, o que teria como consequência a produção de desprazer. Nesse caso, devido à tendência do aparelho a evitar o desprazer - do chamado "princípio de desprazer", tal como Freud o denomina em 1900 - a ocupação préconsciente de tal representação poderia ser retirada, fazendo com que esta caísse sob o domínio do processo primário, isto é, tornando-se inconsciente e insuscetível de se tornar consciente. Esse processo de retirada da ocupação de uma representação pré-consciente é chamado de "repressão".

A ocupação de uma representação pelo Pcs - ou seja, sua incorporação ao processo secundário -, só ocorreria quando nenhum desprazer resultasse dessa ocupação ou quando o desprazer produzido pudesse ser inibido. Sendo assim, dois tipos de representações permaneceriam sob o domínio do processo primário, ou seja, 
permaneceriam insuscetíveis de se tornarem conscientes pela via normal do pensamento: as reprimidas e aquelas vinculadas às moções de desejo que nunca foram integradas ao Pcs. Essas últimas, ao contrário das primeiras, nunca teriam sido incorporadas ao processo secundário, o que quer dizer que elas teriam permanecido inconscientes desde sua origem. Nos Artigos metapsicológicos, de 1915, Freud irá formular a hipótese de que essas representações teriam sido alvo da "repressão primordial", enquanto as primeiras teriam sido alvo da "repressão propriamente dita".

No artigo metapsicológico "O inconsciente", de 1915, Freud apresenta a hipótese de que a constituição das "representações-palavra" seria responsável pela ligação de uma parte da excitação em estado livre e, portanto, seria responsável pelo estabelecimento da diferenciação entre o processo primário e o secundário. Enquanto houvesse apenas "representações-coisa" no aparelho, só haveria processo primário; com a constituição das representações-palavra, as representações-coisa a elas associadas passariam a fazer parte do processo secundário e aquelas que não chegassem a ser associadas a palavras permaneceriam incluídas no processo primário e, portanto, sem acesso à consciência. Diz Freud:

[...] a representação consciente abrange a representação-coisa mais a correspondente representação-palavra, e a inconsciente é a representaçãocoisa somente. O sistema Ics contém as ocupações de coisa dos objetos que são as ocupações de objeto primárias e genuínas; o sistema Pcs nasce quando essa representação-coisa é sobre-ocupada pelo enlace com as representações-palavra que lhe correspondem. Tais sobre-ocupações, podemos conjeturar, são as que produzem uma organização psíquica mais alta e possibilitam a rendição do processo primário pelo secundário, que governa no interior do Pcs [...] A representação não apreendida em palavras, ou o ato psíquico não sobre-ocupado, fica então para trás, no interior do Ics, como algo reprimido" (FREUD, 1915, p. 202).

Nessa passagem, Freud esclarece que as representações reprimidas seriam aquelas que não estariam associadas a palavras. Desde o Projeto... era possível inferir essa associação, mas, apenas em 1915, essa hipótese é explicitamente afirmada.

Na terceira parte de Sobre um caso de paranóia descrito autobiograficamente (1911[1910]), (o “caso Schreber"), há uma descrição da repressão muito próxima daquela presente no artigo metapsicológico sobre a repressão. Ali, Freud distingue três fases desse processo. Na primeira 
etapa, ocorreria uma "fixação", ou seja, uma inibição do desenvolvimento de uma pulsão e a consequente permanência de tal pulsão em um estado mais infantil. Nesse caso, diz Freud, a corrente libidinal correspondente se comporta a respeito das formações psíquicas posteriores como uma que pertença ao sistema do inconsciente, como uma reprimida. Essa primeira etapa da repressão seria pré-condição para a ocorrência da "repressão propriamente dita", a qual corresponderia à segunda etapa da repressão. A repressão propriamente dita partiria dos sistemas suscetíveis de consciência, diz Freud, e se voltaria contra os derivados psíquicos daquelas pulsões fixadas. Quando essas últimas pulsões, devido ao seu fortalecimento, conseguissem se infiltrar no pré-consciente, surgiria um conflito entre elas e as pulsões de acordo com o eu, o que acabaria levando à repressão. Freud discrimina ainda uma terceira fase da repressão, que consistiria no "retorno do reprimido" devido ao fracasso da repressão, o que teria como consequência a regressão do desenvolvimento libidinal.

Em A Repressão (1915), Freud retoma essa descrição exposta no caso Schreber e acrescenta a ela a hipótese de que a primeira etapa da repressão consistiria na repressão primordial. A fixação da pulsão, mencionada em 1911, seria resultado de tal repressão. Diz ele:

[...] temos razões para supor uma repressão primordial, uma primeira fase da repressão que consiste em que ao representante psíquico da pulsão (representante-representação) se nega a admissão na consciência. Assim, se estabelece uma fixação; a partir desse momento, o representante em questão persiste imutável e a pulsão continua ligada a ele (FREUD, 1915, p. 148).

Então, nos Artigos metapsicológicos, Freud passa a diferenciar entre uma "repressão primordial" - que consistiria na recusa do representante de pulsão por parte do pré-consciente ou do processo secundário, o que teria como consequência a fixação desta no Ics - e a "repressão propriamente dita" - que consistiria na retirada da ocupação pré-consciente de uma representação, à qual o representante de pulsão se tivesse associado. ${ }^{4} \mathrm{~A}$ ocupação subtraída seria aquela da representação-palavra. Como vimos, quando a representação-coisa fosse sobre-investida pela palavra, ela passaria a fazer parte do nível de organização superior, isto é, do Pcs; quando tal

4 Como Freud já havia dito no capítulo 7, duas forças cooperariam para a repressão propriamente dita: a repulsão por parte do pré-consciente e a atração exercida pelos desejos inconscientes. 
sobreocupação fosse retirada, a representação-coisa deixaria de fazer parte do Pcs e voltaria a ser incorporada ao Ics (ao processo primário). A representação reprimida seria, portanto, aquela representação-coisa que perdeu o seu vínculo com a palavra (no caso da repressão propriamente dita) ou aquela que nunca teve esse vínculo (no caso da repressão primordial).

Sendo assim, o reprimido primordial consistiria naquelas representações-coisa que nunca foram sobre-investidas pelas representaçõespalavra - que nunca fizeram parte do Pcs - e o reprimido propriamente dito consistiria naquelas representações-coisa que perderam seu vínculo com a palavra, por terem sido associadas ao reprimido primordial e se tornado fonte de desprazer para o Pcs. No capítulo 7, já estava presente a hipótese de que o núcleo do Ics seria constituído por representações que nunca se tornaram pré-conscientes, mas não havia ainda o conceito de repressão primordial; só as representações rechaçadas do Pcs eram consideradas como tendo sido reprimidas e, portanto, o reprimido corresponderia a apenas uma parte do sistema inconsciente. Além disso, Freud introduz, em 1915, a hipótese de que as representações-alvo da repressão primordial são os "representantes de pulsão"; no capítulo 7, estas eram chamadas de "moções de desejo". Fica claro que, nessa etapa da teoria, a repressão é pensada como um processo que nada tem a ver com experiências dolorosas reais, mas sim com a oposição que uma parte de nossos processos psíquicos passa a exercer contra pulsões e desejos. Mas por que certos desejos ou certos representantes de pulsão permaneceriam, desde a origem, excluídos do processo secundário e, portanto, sem acesso à consciência? Em outras palavras, qual seria o motivo da repressão primordial?

No capítulo 7 de A interpretação dos sonhos (1900), Freud atribui o fato de algumas "moções de desejo" não chegarem a ser integradas ao processo secundário ao "estabelecimento tardio" deste último processo. No texto A Repressão (1915), Freud não esclarece em que condições os "representantes de pulsão" seriam alvo da repressão primordial. Permanece, portanto, em aberto a questão sobre qual seria o motivo de tal repressão. De qualquer maneira, nesse momento da teoria, a repressão e a formação do sintoma são pensadas como processos derivados de desejos e da oposição que o processo secundário acaba exercendo sobre estes, de modo que a neurose permanece desvinculada de algo como uma "vivência de dor". Em Inibição, Sintoma e Angústia (1926), no entanto, Freud formula uma hipótese sobre a questão a respeito do motivo da repressão primordial, a qual está relacionada à retomada da reflexão sobre o papel da vivência 
de dor nos processos psíquicos e, na verdade, à colocação desta vivência na origem do psiquismo.

\section{A dor e não o desejo está na origem dos processos psíquicos}

Em Além do princípio do prazer (1920), a "vivência de dor" volta a ser alvo da atenção de Freud. Nesse texto, após concluir pela legitimidade da suposição de um funcionamento que consiste em uma "compulsão à repetição" e que antecede aquele regido pelo princípio do prazer, Freud levanta a questão a respeito de qual seria a função dessa compulsão e em que condições ela afloraria. Em busca de uma resposta a essa questão, ele passa a refletir sobre a reação do aparelho à irrupção de excitações muito intensas - o que agora é definido como "trauma". Essa noção de trauma retoma em muitos aspectos a de vivência de dor formulada no Projeto de uma psicologia. O trauma resultaria da falha dos mecanismos destinados a proteger o aparelho psíquico de excitações muito intensas. Ele estaria relacionado ao despreparo psíquico para a recepção da excitação, à falta do que Freud chama de "preparação para a angústia", a qual consistiria na última trincheira da proteção antiestímulo do aparelho psíquico. Nesse caso, não seria mais possível evitar que este fosse inundado por grandes magnitudes de estímulo e, então, sua tarefa mais urgente passaria a ser ligar psiquicamente os estímulos que irromperam, para conduzi-los, então, a sua tramitação. ${ }^{5}$ Freud conclui, a partir disso, que a função do funcionamento repetitivo que antecede o princípio do prazer seria ligar a excitação e, assim, preparar o terreno para que este último princípio pudesse passar a imperar. Em Inibição, Sintoma e Angústia (1926), essa reflexão sobre o trauma iniciada em 1920 é retomada. A partir de então, a vivência de dor - então chamada de "trauma" - passa a ter um papel fundamental no desenvolvimento dos processos psíquicos, ao ser vinculado à angústia e à repressão.

$\mathrm{Na}$ segunda parte desse texto de 1926, Freud formula uma hipótese sobre a questão que havia permanecido em aberto em sua teoria anterior a respeito dos motivos da repressão primordial, ao afirmar

\footnotetext{
A "dor", que no Projeto... correspondia ao que Freud agora chama de "trauma", passa a ser definida como o desprazer decorrente do rompimento da proteção antiestímulo em um ponto específico.
} 
que: "é inteiramente verossímil que fatores quantitativos, como a intensidade hipertrófica da excitação e a ruptura da proteção antiestímulo constituam as ocasiões imediatas das repressões primordiais" (FREUD, 1926, p. 94). Essa afirmação sugere que seriam os primeiros traumas que levariam à repressão primordial.

$\mathrm{Na}$ continuidade do texto, Freud conclui que a característica em comum presente em todos os afetos de angústia é representar uma "reação a um perigo" e que, nas neuroses, é a angústia que leva à repressão. Ele propõe, então, a hipótese de que o protótipo das experiências de angústia seria o nascimento. Diz ele:

[...] o estado de angústia é a reprodução de uma vivência que reuniu as condições para um aumento do estímulo como o assinalado e para a descarga por determinadas vias, em virtude do qual também o desprazer da angústia recebeu o seu caráter específico. No caso dos seres humanos, o nascimento nos oferece uma vivência arquetípica de tal índole, e por isso nos inclinamos a ver no estado de angústia uma reprodução do trauma do nascimento (FREUD, 1926, p. 133).

No nascimento, argumenta Freud, o "perigo" em questão careceria de todo conteúdo psíquico. O recém-nascido só seria capaz de perceber uma enorme perturbação na economia de sua libido narcisista, e ele repetiria o afeto de angústia em todas as situações que lhe recordassem o nascimento. Mas o que, em outras experiências, traria essa recordação e produziria angústia? - pergunta-se Freud. Ao analisar as ocasiões que produzem angústia na infância, ele conclui que uma condição sempre está presente: a ausência de um objeto altamente estimado, à qual representa para a criança o risco de se ver novamente diante de um aumento de estimulação (o acréscimo da "tensão da necessidade"), ante o qual ela é impotente (assim como na ocasião da "angústia primordial" do nascimento). Assim, ele encontra uma resposta para a questão que havia sido levantada a respeito do que em outras experiências estabelece para a criança a analogia com a situação do nascimento:

[...] a situação da insatisfação em que as magnitudes de estímulo alcançam um nível desprazeroso sem que se as domine por emprego psíquico e descarga, tem que estabelecer para o lactante a analogia com a vivência do nascimento, a repetição da situação de perigo; o comum a ambas é a perturbação econômica pelo incremento das magnitudes de 
estímulo em espera de tramitação, este fator constitui, pois, o núcleo genuíno do "perigo"[...] O menino não precisa guardar do seu nascimento nada mais do que esta caracterização do perigo (FREUD, 1926, p. 137).

Portanto, conclui Freud, a angústia é produto do desamparo psíquico do lactente, o qual é o correspondente óbvio de seu desamparo biológico. Ele estabelece, então, uma relação entre uma série de experiências de angústia que se sucederiam ao longo do desenvolvimento infantil, as quais se remeteriam umas às outras (ou seja, as posteriores àquelas que as antecedem) e todas elas, por fim, ao trauma do nascimento. A experiência primordial de angústia seria, então, o nascimento, no qual o perigo em questão seria o aumento do nível de estimulação, ante o qual se é impotente. Em seguida, a angústia diante da perda do objeto (mãe ou substituto), na qual o perigo assinalado seria o de reviver uma situação de aumento de tensão, por causa da impossibilidade de satisfação das necessidades. A próxima angústia experienciada seria a "angústia de castração", na qual o perigo temido seria a separação dos genitais e a possibilidade de ficar num estado de desamparo diante da libido genital. A seguinte da série seria a angústia diante do Supereu, ou "angústia da consciência moral", a qual assinalaria o perigo de ser castigado pelo Supereu, de perder o seu amor. E a última modificação da angústia, especula Freud, talvez seja a angústia da morte: a angústia em vista da projeção do Supereu nos poderes do destino, diz ele.

Como comenta Laplanche (1987), após dizer que o nascimento é o protótipo dos estados de angústia, Freud recorda a sua teoria geral dos afetos, teoria que faz destes a reprodução de reações antigas que em seu tempo tiveram a sua significação e foram, então, fixadas. Assim como nos histéricos encontramos reações afetivas cuja origem repousa em acontecimentos antigos, os afetos típicos dos seres humanos, observa Laplanche, seriam uma espécie de acesso histérico genérico, fixados e, a partir de então, congênitos.

Freud vincula os diferentes tipos de neuroses aos diferentes tipos de angústia. Na histeria de conversão, a angústia central - que levaria à repressão e à neurose - seria a angústia perante o perigo de perder o amor do objeto. Nas fobias, seria a angústia de castração e, na neurose obsessiva, a angústia perante o Supereu:

Agora sabemos que não corremos perigo de declarar a angústia de castração como o único motor dos processos defensivos que levam à neurose. Em outro lugar, comentei como o desenvolvimento da menina pequena é guiado através do complexo de castração até o investimento terno de 
objeto. E, precisamente, no caso da mulher parece que a situação de perigo da perda de objeto continua sendo a mais eficaz. A respeito da condição de angústia válida para ela, temos direito de introduzir essa pequena modificação: mais que da ausência ou da perda real do objeto, se trata da perda de amor da parte do objeto. Posto que sabemos com certeza que a histeria tem maior afinidade com a feminilidade, assim como a neurose obsessiva com a masculinidade, isso nos sugere a conjectura de que a perda de amor como condição de angústia desempenha na histeria um papel semelhante à ameaça de castração nas fobias, e a angústia frente ao supereu na neurose obsessiva (FREUD, 1926, p. 143).

Como observa Laplanche, essas ideias elaboradas por Freud, nesse momento, têm como consequência a relativização do papel da castração na determinação das neuroses. Diz ele:

[...] quando Freud é levado a traçar em suas linhas gerais, uma espécie de correspondência entre esses perigos e as formas psicopatológicas, percebese que a castração deixa de ser o ponto central de tudo, uma vez que seria essencial numa única neurose, a fobia (LAPLANCHE, 1988, p. 142).

Laplanche, contudo, parece considerar que essas modificações introduzidas por Freud consistem numa espécie de retrocesso, com relação aquilo que havia sido anteriormente alcançado. Segundo ele, nesse momento, Freud "esquece um certo número de conceitos, de instrumentos que ele tinha, por outro lado, a sua disposição e que haviam sido elaborados por ele mesmo" (LAPLANCHE, 1988, p. 146). Contudo, em vez de descartarmos, de imediato, certos aspectos da teoria freudiana que podem parecer, à primeira vista, inconsistentes com suas hipóteses anteriores, talvez seja mais frutífero nos perguntarmos pelos motivos que levaram Freud a introduzir essas modificações e buscarmos explorar as suas consequências para uma teoria sobre o funcionamento do psiquismo.

Com essa hipótese de que o nascimento seria uma vivência traumática originária, ocasião de uma "angústia primordial", que atribuiria um caráter traumático a uma série de vivências posteriores - e uma série de angústias posteriores - que estariam na base da repressão, Freud volta a colocar na origem do psiquismo e das neuroses experiências traumáticas reais. Na verdade, a vivência de dor não só é retomada nessa etapa final da obra freudiana como passa a ser pensada como sendo a mais fundamental no desenvolvimento dos processos psíquicos. 
Essas ideias elaboradas por Freud, em 1926, parecem conduzir à vinculação entre o reprimido primordial e os primeiros traumas (o nascimento e outros traumas iniciais). Dado que Freud formula a hipótese de que na base da repressão primordial estariam experiências traumáticas (irrupção de grandes quantidades de excitação devido à ruptura da proteção antiestímulo), e dado que o nascimento seria uma vivência traumática originária que conferiria caráter traumático a certas experiências posteriores, então, o nascimento e outros traumas iniciais seriam as ocasiões das repressões primordiais. A angústia pela perda do amor da mãe, a angústia de castração e a angústia perante o Supereu seriam o motores da "repressão propriamente dita". Ou seja, certos impulsos libidinais e agressivos posteriores - como aqueles envolvidos no complexo de Édipo passariam a representar para a criança "perigos" por se associarem ao reprimido primordial e recolocarem a possibilidade de se reviver uma situação traumática.

Dado que a repressão primordial não é um mecanismo envolvido apenas na neurose, mas é um mecanismo constitutivo do funcionamento psíquico - constitutivo da diferenciação entre processo primário e secundário -, podemos dizer que, com essas hipóteses apresentadas em 1926, Freud não só recoloca a vivência de dor na base das neuroses, mas a coloca como estando na base de todos os processos psíquicos e como sendo, inclusive, mais fundamental do que a vivência de satisfação e o desejo que dela deriva. Mais uma vez, a metáfora de Luiz Roberto Monzani (1989), do movimento em espiral, revela-se insuperável para descrever o movimento do pensamento freudiano: teses anteriormente formuladas são retomadas, num momento posterior da obra, em um outro contexto e em um outro plano de significação.

\section{CONSIDERAÇÕES FINAIS}

Inicialmente, em seu Projeto de uma psicologia, Freud vincula a neurose à vivência de dor e coloca essa vivência, ao lado da vivência de satisfação, como sendo estruturante do psiquismo. Com a percepção de que a gênese das neuroses estava relacionada a fantasias e não a experiências de sedução efetivamente vivenciadas, ele abandona a hipótese de que haveria uma experiência traumática real envolvida na gênese das neuroses. A partir de então, o papel da vivência de dor é deixado de lado e o desenvolvimento dos processos psíquicos passa a ser pensado segundo o modelo da vivência de satisfação exclusivamente. De acordo com a teoria desenvolvida a partir de $A$ interpretação dos sonhos, apenas o desejo estaria na base dos processos 
psíquicos normais e patológicos. O central na teoria freudiana das neuroses passa a ser a repressão de um desejo que se torna fonte de desprazer por entrar em conflito com as exigências morais impostas pela cultura ao indivíduo. Podemos dizer que o papel da cultura na gênese das neuroses na verdade, o conflito entre o pulsional e o cultural - permanece em primeiro plano. Não há, nesse período, a necessidade de se supor que sejam traumas reais que confiram valor traumático a certos impulsos e experiências, levando à repressão e, possivelmente, aos sintomas neuróticos.

Em Inibição, Sintoma e Angústia, contudo, com a vinculação entre o reprimido primordial e os primeiros traumas e com a vinculação de todas as experiências de angústia ao trauma do nascimento, Freud não só volta a colocar a vivência de dor na base das neuroses, como passa a situá-la na base de todos os processos psíquicos. O trauma do nascimento e a contínua ameaça de reviver esse trauma, por causa do desamparo inicial da criança e da sua dependência absoluta de outra pessoa, passam a ser pensados como o fundamento sobre o qual o psiquismo se desenvolve. Assim, o ser humano teria uma predisposição biológica, constitucional, à neurose, ou seja, sua condição biológica de prematuração e desamparo ao nascer seria o fator predisponente a esta. Portanto, se no momento anterior as neuroses seriam, de certa forma, inevitáveis pela necessidade de repressão de parte dos nossos impulsos instintivos - e aí o conflito entre o cultural e o pulsional estava em primeiro plano -, em 1926, Freud passa a situar na base das neuroses, ao lado desse fator cultural e igualmente ou até mais fundamental e inevitável do que ele, um fator biológico.

No fim desse texto de 1926, Freud observa que três fatores influenciam na causação das neuroses:

1. um "fator biológico": o prolongado desamparo e dependência da criatura humana, seu estado de prematuração ao nascer que:

[...] reforça o influxo do mundo exterior real, promove prematuramente a diferenciação do eu a respeito do isso, eleva a significação dos perigos do mundo exterior e aumenta enormemente o valor do único objeto que pode proteger destes perigos e substituir a vida intrauterina perdida. Assim, esse fator biológico produz as primeiras situações de perigo e cria a necessidade de ser amado, de que o homem não se livrará mais (FREUD, 1926, p.154-155).

2. um "fator filogenético": o desenvolvimento descontínuo da vida sexual do ser humano, ou seja, a interrupção nesta que ocorre no período de latência: 
A significação patógena deste fator se deve a que a maioria das exigências pulsionais dessa sexualidade infantil são tratadas como perigos pelo eu, que se defende delas como se fossem tais, de modo que as posteriores moções sexuais da puberdade, que deveriam estar de acordo com o eu, correm o risco de sucumbir à atração exercida pelos arquétipos infantis e segui-lo à repressão. Topamos aqui com a etiologia mais direta das neuroses. É notável que o prematuro contato com as exigências da sexualidade exerça sobre o eu um efeito parecido ao prematuro contato com o mundo exterior (FREUD, 1926, p. 155).

3. um "fator psicológico": a imperfeição de nosso aparelho psíquico estreitamente relacionada com sua diferenciação em um eu e um isso, a qual em última análise, diz Freud, também remonta ao influxo do mundo exterior", pois:

a consideração pelos perigos da realidade força o eu a colocar-se na defensiva ante certas moções pulsionais do isso, a tratá-las como perigo. No entanto, o isso não pode se proteger de perigos pulsionais internos de maneira tão eficaz como de uma porção da realidade que lhe é alheia. Conectado intimamente com o isso, só pode se defender do perigo pulsional limitando sua própria organização e havendo-se com a formação do sintoma como substituto do dano que infligiu à pulsão (Freud, 1926, p. 155-56).

Essas considerações de Freud em Inibição, Sintoma e Angústia, deixam claro o papel que as experiências traumáticas originárias desempenhariam no desenvolvimento dos processos psíquicos e na etiologia das neuroses. Haveria um fator biológico - a prematuração e o desamparo inicial do ser humano - que acentuaria o valor traumático de certas experiências, e esses traumas iniciais seriam o fundamento da repressão e interfeririam diretamente, como ele argumenta acima, nos outros fatores que predisporiam o ser humano à neurose. Assistimos, portanto, nessa etapa da obra freudiana, não só a uma retomada e colocação em primeiro plano da vivência de dor, mas também a uma acentuação do papel do fator biológico na determinação das neuroses.

Essa vinculação das neuroses a experiências traumáticas primárias impõe uma série de modificações à concepção freudiana das neuroses, as quais não parecem ter sido exaustivamente exploradas pelos estudiosos da psicanálise. Entre essas modificações, podemos mencionar:

1. O papel do conflito entre os impulsos e a moralidade na gênese das neuroses é relativizado e, portanto, a determinação sexual das neuroses é relativizada. 
2. O estado de prematuração do ser humano ao nascer - que será depois também enfatizado por Lacan, embora em um sentido diferente de Freud - passa a ser fator central na etiologia das neuroses.

3. A relação entre os diversos tipos de neuroses e as etapas do desenvolvimento é modificada. Até então, Freud havia sustentado a hipótese de que o ponto de fixação da neurose obsessiva seria a fase anal, enquanto que o da histeria seria a fase fálica. De acordo com isso, a neurose obsessiva estaria relacionada a uma fase mais prematura do desenvolvimento psicosexual do que a histeria. Essas modificações introduzidas em Inibição, Sintoma e Angústia, modificam essas hipóteses. Embora a histeria continue tendo como núcleo a fixação na fase fálica, a angústia central que levaria à repressão seria uma angústia mais primitiva do que a característica dessa fase. Por outro lado, a angústia envolvida na determinação da neurose obsessiva seria posterior ao complexo de Édipo, dado que pressuporia a constituição do Superego. Assim, a histeria passa a ser pensada como um tipo de neurose mais primitiva do que a neurose obsessiva.

Em trabalhos posteriores, buscaremos explorar os motivos que levaram Freud a introduzir essas novas hipóteses em sua teoria nesse momento, assim como as suas consequências, para uma teoria das neuroses e do funcionamento psíquico em geral.

\section{REFERÊNCIAS}

CAROPRESO, F.; SIMANKE, R. T. A linguagem de órgão esquizofrênica e o problema da significação na metapsicologia freudiana. Revista de Filosofia: Aurora, Curitiba, v. 18 , n. 23 , p. 105-128, 2006.

CAROPRESO, F. Freud e a natureza do psíquico. São Paulo: AnnaBlume; FAPESP, 2009. (No prelo).

FREUD, S. Project for a scientific psychology. The Standard Edition of the Complete Psychological Works of Sigmund Freud, v. 1, p. 283-387, 1975. (Publicado originalmente em 1950 [1895]). 
Extracts from the Fliess Papers. The Standard Edition of the Complete Psychological Works of Sigmund Freud, v. 1, p. 175-280, 1975. (Publicado originalmente em 1950 [1892-1899]).

The interpretation of dreams (Second Part). The Standard Edition of the Complete Psychological Works of Sigmund Freud, v. 5, p. 339-621, 1975. (Publicado originalmente em 1900).

Psycho-analytic notes on an autobiographical account of a case of paranoia. The Standard Edition of the Complete Psychological Works of Sigmund Freud, v. 12, p. 3-82, 1975. (Publicado originalmente em 1911).

Papers on metapsychology. The Standard Edition of the Complete Psychological Works of Sigmund Freud, v. 14, p. 105-215, 1975. (Publicado originalmente em 1915).

Beyond the pleasure principle. The Standard Edition of the Complete Psychological Works of Sigmund Freud, v. 18, p. 3-66, 1975. (Publicado originalmente em 1920).

Inhibitions, Symptoms and Anxiety. The Standard Edition of the Complete Psychological Works of Sigmund Freud, v. 20, p. 77-178, 1975. (Publicado originalmente em 1926).

LAPLANCHE, J.; PONTALIS, J-B. Vocabulário da psicanálise. Martins Fontes, 1982.

LAPLANCHE, J. Problemáticas I: A angústia. São Paulo: Martins Fontes, 1987.

Problemáticas II: Castração - simbolizações. São Paulo: Martins Fontes, 1988.

MONZANI, L. R. O movimento de um pensamento. Campinas: Ed. da Unicamp, 1989.

SIMANKE, R. T. Mente, cérebro e consciência nos primórdios da metapsicologia freudiana: uma análise do "Projeto de uma Psicologia" (1895). São Carlos: Edufscar, 2007.

Recebido: 10/09/2009

Received: 09/10/2009

Aprovado: 20/10/2009

Approved: 10/20/2009 